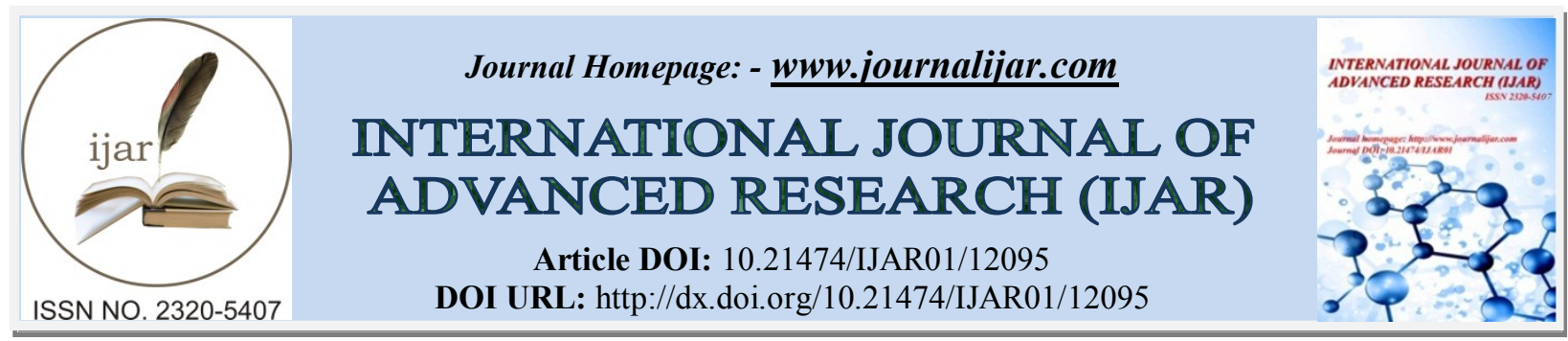

RESEARCH ARTICLE

\title{
REVIEW ON ROLE OF METAL SALT IN THE RE-MINERALIZATION OF DENTAL CARIES
}

\section{Isha Bisla}

Library dissertation work submitted in the Department of Pedodontics and Preventive Dentistry, as a part of MDS research, Swami Devi Dyal Hospital and Dental College, Barwala, Panchkula, Pundit Bhagwat Dayal Sharma University of Health Sciences, Rohtak, Haryana, India, 132001.

\section{Manuscript Info}

............................

Manuscript History

Received: 25 September 2020

Final Accepted: 28 October 2020

Published: November 2020

Key words:-

Dental Caries, Re-Mineralisation, TriCalcium Phosphate (Tcp) (Clinpro $^{\text {tm }}$ ), Amorphous Calcium Phosphate (Enamelon $^{\text {tm }}$ ), Calcium Carbonate Carrier $\quad$ Sensistat $^{\text {tm }}$ ), Calcium Hydroxide, Casein PhosphopeptideAmorphous Calcium Phosphate Cpp Acp(Recaldent ${ }^{\text {tm }}$ And Mi Paste $\left.{ }^{\mathrm{Tm}}\right)$, Cpp - Acpf (Mi Paste Plus ${ }^{\text {tm }}$ ), Nano Hydoxyapatite $\left(\right.$ Reminpro $\left.^{\text {tm }}\right)$, Sodium Calcium Phosphosilicate-Bioactive Glass (Novamin ${ }^{\mathrm{tm}}$ )

Corresponding Author:- Isha Bisla

Address:- House No 349, Sector $8 \& 9$ Part-2 Urban Estate, Karnal 132001 Haryana, India.

\section{Abstract}

Dental caries is a most common disease that affects large number of people. It is a worldwide public health problem, affecting numerous urban and rural communities. White-spot lesions (WSL) are the earliest macroscopic evidence of enamel caries. Typically, the enamel surface layer stays intact during subsurface demineralization, but, without treatment, will eventually collapse into a full cavity. Near-neutral $\mathrm{pH}$ of saliva is endowed with a natural buffering capacity. Natural demineralization of tooth at an early stage is reversed by saliva, which contains calcium ions, phosphate ions, buffering agents, fluoride, and other substances. The strategy for aided remineralisation is to have ions directly delivered to where and when they are needed the most. Several mechanisms are available for aided remineralisation. The most well known is the delivery of topical and systemic fluoride, which has been proven to be a highly effective measure for prevention of caries. However limitations and risks associated with the use of fluoride as a remineralising agent fuelled the need to develop newer non-toxic techniques that deliver calcium and phosphate ions directly into subsurface lesion and/or boost remineralising properties of saliva. Encouraging microscopic changes in the demineralized enamel surface following the treatment with different concentration of metal salts, involving zinc, strontium, magnesium, in addition to stannous fluoride, many metal salts are in use for the treatment of dental caries. Microscopic examination was conducted on teeth samples before and after pH-cycling procedure and following the treatment with the selected metal salt under polarized microscope (100X). The best obvious remineralisation was found following treatment with stannous fluoride, followed by zinc chloride. The stannous fluoride was the best in the remineralisation of initial caries, results for other metals seem to be promising if used for prevention of dental caries. Mineralization of teeth is determined by major inorganic elements as calcium, phosphorous in addition to other elements that occur in traces within tooth structure (Thylstrup and Fejerskov, 1996; Murry, 1996; Peter, 2004). Fluoride now a day is widely used either systemically or topically to increase resistance of teeth surface, it has been well documented as a major contributing factor in the decline of the incidence and severity of dental caries in many countries (Murry, 1996; 
Curzon,1999).So far fluoride has been considered to play an almost unique role in the prevention of dental caries; however there is no reason to dismiss the role of other elements as being potential cariostatic agents. Different concentrations of different metal ions as zinc and copper have been tested for better effect on remineralisation in vitro (Dedhiya, et al., 1974; Fang et al., 1980). However controversy is present in the literature concerning their effectiveness in prevention of dental caries when used topically at effective concentrations (Torredo et al., 2004; Elzbieta et al., 2008; Curzon, 1983).

Copy Right, IJAR, 2020,. All rights reserved.

\section{Introduction:-}

The primary prevention of dental caries involves the increase in the resistance of the outer enamel surface to acid dissolution and enhancement of remineralization (Thylstrup and Fejerskov, 1996). The zinc and strontium chloride were based in a study on the knowledge regarding their inverse relation to dental caries. Observational studies showed that there is an inverse co-efficient correlation between the level of zinc and strontium ions in teeth and/or saliva and severity of dental caries (Duggal et al. 1991; El -Samarrai et a., 2001). Experimental studies are also present regarding the cariostatic effect of zinc ion when used alone or in combination with others on the increased resistance of outer enamel surface to carious lesion (Torredo et al., 2004). Magnesium on the other hand was reported to have a direct relation with dental caries. Observational studies showed a positive/or no correlation between magnesium level in teeth and dental caries (El-Samarrai et al., 2001). It is well documented that stannous fluoride is effective in the remineralisation of initial carious lesion and increase the resistance against caries attack (Mellberg, 1990). Under polarized light microscope the ground section of carious enamel surface indicated a high loss of minerals. The hypo mineralization was found to decrease from the outer to inner layers of enamel. However a clear demarcation between different zones of the carious lesion was not obvious. For natural carious lesion four zones are present starting from the translucent zone in the inner layer of enamel, dark zone, body lesion, and intact layer. The microscopic changes of enamel surface following application of metal ions were observed. A various degree of remineralisation was observed for different metal salts. A higher remineralisation was observed for stannous fluoride followed by zinc chloride while samples treated by strontium chloride showed a relatively a thin and poorly mineralized enamel layers. Enamel layers treated with magnesium chloride remained hypo mineralized confirming the cariogenic effect of this element. The cariostatic potential of zinc chloride and strontium ions chloride need to be confirmed by further studies, experimental as well as animal studies on an artificial as well as natural carious lesion before considering them really as anti cariogenic element and before giving any recommendation for them to be used topically in the dental clinical practice. The optical appearance of white spot lesion was decreased after applying remineralizing products while Sodium Fluoride demonstrated better potency on changing the white spot lesion. White spot lesion is one of undesirable complications, occurring on enamel surfaces during fixed orthodontic treatment, especially in the poor oral hygiene patients.(Chang et al., 1997; Tufekci et al., 2011). Orthodontic patients experience difficulty in brushing teeth from the beginning of treatment due to increasing of plaque retention site. Acidogenic bacterium in plaque cause low $\mathrm{pH}$ and lead to imbalance between demineralization and remineralization cycle. When remineralization is overcome, white spot lesions are formed.(Chang et al., 1997; Lau and Wong, 2006; Bishara and Ostby, 2008). Optical appearance of the lesion comes from changing of difference between refractive index of sound \& abnormal enamel. When the light reflection differs, the lesion can be seen as white spot and it may compromise the esthetics of patient's smile (Benson, 2008). Now a days, various products claim to have remineralizing potential. (Lynch et al., 2000; Bergstrand and Twetman, 2003; Azarpazhooh and Limebac,2008; Pulido, et al., 2008). Thus many evaluating processes come up to measure white spot lesion both macroscopically and microscopically depend on purpose of application. Various investigations in vitro and in vivo have shown effect of remineralizing agents on white spot lesion measured by subsurface remineralisation, lesion depth, mineral content, surface micro-hardness and fluoride uptake, for instance.(Brochner et al., 2010). However, few studies demonstrated optical properties change, which is a factor that patient might concern about more than molecular change of the lesion. Fortunately, another interesting method in defining enamel demineralization by using photographic technique with computerized image analysis, was proposed. Researchers have shown that under controlled circumstances and appropriate camera angle, this method is not only reproducible but also cheap and accessible.(Livas et al., 2008; Willmot, 2008). 


\section{Review of literature:-}

Remineralisation of white spot and carious lesions of teeth is possible with the use of many currently available non fluoride metal salt formulations as follows.

1. Tri-calcium Phosphate (TCP) With Fluoride $\left(\right.$ Clinpro $\left.^{\mathrm{TM}}\right)$

2. Amorphous Calcium Phosphate With Fluoride (Enamelon ${ }^{\mathrm{TM}}$ )

3. Calcium Carbonate Carrier (SensiStat ${ }^{\mathrm{TM}}$ )

4. Calcium hydroxide

5. Complex of Casein Phosphopeptide-Amorphous Calcium Phosphate CPP - ACP(Recaldent ${ }^{\mathrm{TM}}$ And MI Paste ${ }^{\mathrm{TM}}$ )

6. $\mathrm{CPP}-\mathrm{ACPF}\left(\mathrm{MI}\right.$ Paste Plus ${ }^{\mathrm{TM}}$ )

7. Nano Hydoxyapatite (Reminpro ${ }^{\mathrm{TM}}$ )

8. Sodium Calcium Phosphosilicate-Bioactive Glass $\left(\right.$ Novamin $^{\mathrm{TM}}$ )

\section{Tricalcium Phosphate (TCP)( CLINPRO $\left.{ }^{\mathrm{TM}}\right)$ :}

Tricalcium phosphate has the chemical formula $\mathrm{Ca}_{3}(\mathrm{PO} 4)_{2}$, and exists in two forms, alpha and beta. Alpha TCP is formed when human enamel is heated to high temperatures. It is a relatively insoluble material in aqueous environments $(2 \mathrm{mg} / 100 \mathrm{~mL}$ in water) (Aminzadeh et al., 1999; Feuerstein et al., 2005). Crystalline beta TCP can be formed by combining calcium carbonate and calcium hydrogen phosphate, and heating the mixture to over 1000 degrees Celsius for 1 day, to give a flaky, stiff powder (Laurence, 2009). Clinpro ${ }^{\mathrm{TM}}$ is a new hybrid material created with a milling technique that fuses beta TCP and sodium lauryl sulfate or fumaric acid with fluoride. This blending results in "functionalized" calcium and a "free" phosphate, designed to increase the efficacy of fluoride remineralisation. Beta TCP is similar to apatite structure and possesses unique calcium environments capable of reacting with fluoride and enamel. When the phosphate floats freely, the exposed calcium environments are protected by preventing the calcium from prematurely interacting with fluoride. TCP provides catalytic amounts of calcium to boost fluoride efficacy and may be well designed to coexist with fluoride in a mouth rinse or dentifrice because it will not react before reaching the tooth surface. When TCP finally comes into contact with the tooth surface and is moistened by saliva, the protective barrier breaks down, making the calcium, phosphate and fluoride ions available to the teeth. The fluoride and calcium then reacts with weakened enamel to provide a seed for enhanced mineral growth relative to fluoride alone. A major problem with use of TCP is the formation of calcium phosphate complexes, or if fluorides are present, formation of calcium fluoride occurs which inhibit remineralisation by lowering the levels of bio-avaliable calcium and fluoride (Laurence, 2009). For this reason, TCP levels would have to be kept very low, in the order of less than $1 \%$. To overcome such problems, TCP can be combined with a ceramic such as titanium dioxide, or other metal oxides (Nidhi and Kunwarjeet, 2012). It has been suggested that the organic coating prevents undesirable interactions with fluoride, but may dissolves away when particles contact saliva (Karlinsey et al., 2010). Products available with TCP include a $5000 \mathrm{ppm}$ sodium fluoride dentifrice and a $5 \%$ sodium fluoride varnish. Studies have concluded that TCP provided superior surface and sub-surface remineralisation compared with a 5000 ppm fluoride and CPP-ACP (Sashi et al., 2013; Karlinsey et al., 2010).

The potential of TCP is promising, but more studies are needed, including clinical trials supporting its efficacy in boosting remineralisation.

Amorphous Calcium Phosphate (ACP, ENAMELON ${ }^{\mathrm{TM}}$ ):

ACP was firstly described by Aaron S. Posner in the mid1960s (Boskey, 1997). It was obtained as an amorphous precipitate by accident when mixing high concentrations $(30 \mathrm{~mm})$ of calcium chloride and sodium acid phosphate $(20 \mathrm{~mm}$ ) in buffer (Eanes et al., 1965). It is also used as filler in ionomer cements to fill carious lesions or as a colloidal suspension in toothpastes, chewing gums or mouthwashes to promote demineralization of carious lesions and/or to prevent tooth demineralization (Zhao et al., 2011). The ACP technology was developed by Dr. Ming S. Tung (Goswami et al., 2012). The ACP technology requires a two-phase delivery system to keep the calcium and phosphorous components from reacting with each other before use. The current sources of calcium and phosphorous are two salts, calcium sulfate and di-potassium phosphate. When the two salts are mixed, they rapidly form ACP that can precipitate onto the tooth surface. This precipitated ACP can then readily dissolve into the saliva and can be available for tooth remineralisation (Goswami et al., 2012; Tung and Eichmiller, 1999). ACP would act as a calcium phosphate reservoir, buffering the activities of free $\mathrm{Ca}^{+2}$ and $\mathrm{PO}_{4}^{-3}$ ions in the plaque fluid, helping to maintain a state of super-saturation of these ions, thereby depressing enamel demineralization and enhancing remineralisation (Reynolds, 1991). In 1999, ACP was incorporated into toothpaste called Enamelon ${ }^{\mathrm{TM}}$ and later reintroduced in 2004 in Enamel Care toothpaste by Church and Dwight. It is also available as Discus Dental's Nite White Bleaching Gel and Premier Dental's Enamel Pro Polishing Paste. It is also used in the Aegis product line, such as Aegis Pit and 
Fissure Sealant, produced by Bosworth (Goswami et al., 2012; Sullivan et al., 1997) . An inherent technical issue with Enamelon ${ }^{\mathrm{TM}}$ is that calcium and phosphate are not stabilized, allowing the two ions to combine into insoluble precipitates before they come into contact with saliva or enamel.

\section{Calcium Carbonate Carrier (Sensistat ${ }^{\mathrm{TM}}$ ):}

The sensiStat ${ }^{\mathrm{TM}}$ technology was developed by Dr. Israel Kleinberg of New York. The technology was first incorporated into Ortek's proClude ${ }^{\mathrm{TM}}$ desensitizing prophy paste and later in DenClude ${ }^{\mathrm{TM}}$. Sensistat ${ }^{\mathrm{TM}}$ technology is made of arginine bicarbonate, an amino acid complex, and calcium carbonate (Mcclure,1963). Arginine complex is responsible for holding the calcium carbonate particles to the tooth surface and allows the calcium carbonate to slowly dissolve and release calcium which is then available to remineralise the tooth surface.

\section{Calcium Hydroxide:}

Since the introduction of calcium hydroxide to dentistry by Hermann in 1936, it has been indicated to promote healing in many clinical situations. However, the initial reference to its use has been attributed to Nygren (1838) for the treatment of the 'fistula dentalis', whilst Codman (1851) was the first to attempt to preserve the involved dental pulp. According to Cvek (1989) calcium hydroxide became more widely known in the 1930s through the pioneering work of Hermann (1936) and after the introduction of this material in the United States (Teuscher \& Zander 1938, Zander 1939). The first reports dealing with successful pulpal healing using calcium hydroxide appeared in the literature between 1934 and 1941. Since then, and mainly after the Second World War, the clinical indications for its use were expanded and now this chemical is considered the best medicament to induce hard tissue deposition and promote healing of vital pulpal and periapical tissues (Garcia 1983).

Calcium hydroxide is a material which has been used for a variety of purposes since its introduction into dentistry in the early part of the twentieth century. In its pure form, the substance has a high $\mathrm{pH}$ (12.5), only soluble in water with a solubility of $1.2 \mathrm{~g} / \mathrm{l}$ at a temperature of $25^{\circ} \mathrm{C}$ and its dental use relates chiefly to its ability to stimulate mineralization, and also to its antibacterial properties (Foreman and Barnes, 1990). In 1912, Head was the first author to suggest that carious dentin could be re-hardened in a similar manner as enamel (Head, 1912). Several studies advocating the philosophy of leaving a layer of carious dentin capped with calcium hydroxide in deep cavities where pulp exposure would be highly probable reported increased radiopacity after treatment and harder dentin whereas other authors have shown evidence of carious dentin remineralisation of the same deep remaining layer, by means of different methodologies and utilizing several materials, including calcium hydroxide (Palazzi, 1966; Kato and Fusayama, 1970; Gupta et al., 1998; Kardos et al., 1999). Ardeshna et al.(2002 ) reported that aqueous calcium hydroxide paste was more effective than calcium hydroxide points at raising the $\mathrm{pH}$ on the external root surface of extracted teeth. Herman demonstrated the formation of dental bridge in an exposed pulpal surface and now it is considered as the "gold standard" for direct pulp capping agent (Hilton, 2009).

Mechanism of action calcium hydroxide is that it's high $\mathrm{pH}$ causes irritation of the pulp tissue, which stimulates repair of dentin by the release of bioactive molecules such as Bone Morphogenic Protein and Transforming Growth Factor-Beta One (Hilton, 2009; Graham et al., 2006). Elevated pH of calcium hydroxide activates alkaline phosphatase from the tissue. This is hydrolytic enzyme that liberates phosphate from esters of phosphates. This phosphate ion, once free, reacts with calcium ion from the blood stream to form a precipitate, calcium phosphate, in the organic matrix. This precipitate is the molecular unit of hydroxyapatite.

Antimicrobial activity of calcium hydroxide is due to the hydroxide ions which promote enzymatic inhibition of microorganisms (Estrela, 1995). Drawbacks of calcium hydroxide as remineralisation agent are: Inadequate strength, Long term solubility, lack of chemical and mechanical adhesion to the surrounding hard tissues, tunnel formation seen in dentinal bridge, accelerated degradation after being acid etched during bonding procedures.(Mickenautsch et al. 2010).

\section{Casein Phosphopeptide-Amorphous Calcium Phosphate (CPP-ACP) GC Tooth Mousse ${ }^{\mathrm{TM}}$, MI Paste ${ }^{\mathrm{TM}}$,} Recaldent $^{\mathrm{TM}}$ ):

In the late 1950's, dairy products were discovered as a food group that could be effective in preventing dental caries. Studies were conducted using dairy products to verify the correlation with caries control. Epidemiological reports suggested that children and adolescents with low incidence of dental caries drank more milk than those with high caries incidence. More recently, studies have shown that children with high consumption of soft drinks relative to consumption of milk and real fruit juice are at higher risk of developing dental caries. (Shaw, 1954). The theory 
behind this possible characteristic involved a high calcium and phosphate content and the presence of the phosphoprotein casein, although other fractions of milk could also play an important role of caseins account for roughly $80 \%$ of the total protein in bovine milk, and exist primarily as calcium phosphate stabilized micellar complexes. This protein, when incorporated into dental biofilm, is associated with an increase in the content of calcium and phosphate inside this environment (Reynolds, 1997), which are the principal components of hydroxyapatite. From insoluble acid casein to soluble sodium caseinate, many forms of this protein were evaluated since attention to its apparent anticariogenic activity was initially observed (Reynolds, 1997; Reynolds et al., 1995). The problem encountered in trying to add the protein to food was the required high levels at which the protein would impart its anticariogenic properties. The levels found to be effective would fail to combine organoleptic properties and the virtue of preventing enamel demineralization (Aimutis, 2004; Reynolds et al., 1995). Since adding casein in its original form to products for public consumption was clearly not feasible, one probable solution was to break apart the molecule in active peptides.

In order to verify the efficacy of the casein molecule when broken apart, it was found that the peptides released by trypsin during a tryptic digestion of caseinate did not destroy the supposed ability to prevent enamel demineralization in situ (Reynolds, 1987). Furthermore, elevated concentrations of these casein peptides, phosphorous and calcium were found in plaque (Reynolds, 1987). This findings prompted investigators to focus their work on casein peptides. In 1987, study demonstrated that the peptides responsible for caseinates supposed anticariogenic activity were the calcium-phosphate stabilizing casein phosphopeptides (CPP) (Reynolds, 1987). The cluster of phosphoseryl residues contained in these peptides can greatly increase the solubility of calcium phosphate (Reeves and Latour, 1958), by forming colloidal casein-phosphopeptide amorphous-calcium-phosphate complexes (Schmidt, 2002). In summary, "CPP-ACP would act as a calcium phosphate reservoir, buffering the activities of free $\mathrm{Ca}^{+2}$ and $\mathrm{PO}_{4}{ }^{-3}$ ions in the plaque fluid, helping to maintain a state of super-saturation of these ions, thereby depressing enamel demineralization and enhancing mineralization" (Reynolds, 1991). The CPP-ACP complex was patented by the University of Melbourne in Victoria, Australia, and the Victorian Dairy Industry Authority in Abbotsford, Victoria, Australia by Eric C. Reynolds (Reynolds, 1991). Bonlac Foods Limited (an Australian company owned by 2,300 dairy farmers in Victoria and Tasmania has retained exclusive manufacturing and marketing rights for CPP-ACP and is the owner of the trademark Recaldent ${ }^{\mathrm{TM}}$. The U.S. Food and Drug Administration (FDA) has approved products marketed in the United States containing the Recaldent ${ }^{\mathrm{TM}}$ technology such as sugar-free gum, Trident Xtra Care ${ }^{\mathrm{TM}}$, Cadbury, MI Paste ${ }^{\mathrm{TM}}$, and MI Paste Plus ${ }^{\mathrm{TM}}$ with 900 parts per million fluoride. Outside of the United States, MI Paste ${ }^{\mathrm{TM}}$ and MI Paste Plus ${ }^{\mathrm{TM}}$ are marketed as Tooth Mousse ${ }^{\mathrm{TM}}$ and Tooth Mousse Plus ${ }^{\mathrm{TM}}$ by GC Europe. MI Paste ${ }^{\mathrm{TM}}$ and MI Paste Plus ${ }^{\mathrm{TM}}$, marketed by GC America, is intended to be primarily used as an abrasive prophylaxis paste and secondarily for the treatment of tooth sensitivity after bleaching procedures, ultrasonic scaling, hand scaling, or root planning (Walsh et al., 2009). However, its use for remineralising dentin and enamel and preventing dental caries is an off-label application (Azarpazhooh et al., 2008). The thought behind this off-label use is that the Recaldent ${ }^{\mathrm{TM}}$ technology provides a delivery system for bioavailable calcium and phosphate ions, enhancing the remineralisation capabilities of fluoride in forming fluorapatite (Reynolds, 2009). The proposed mechanism of anti-cariogenicity of CPP-ACP is that it acts as a calcium-phosphate reservoir. It buffers the activities of free calcium and phosphate ions in the plaque fluid at the tooth surface helping to maintain a state of super-saturation with respect to enamel mineral. The bioavailability of these remineralizing ions safeguards the enamel surface from acidogenic attack, thereby depressing enamel demineralization during these cariogenic challenges and enhancing the subsequent remineralisation of the enamel (Reynolds, 1997). Reynolds and colleagues reported that CPP-ACP binds readily to the surface of the tooth, as well as to the bacteria in the plaque surrounding the tooth. In this way, CPP-ACP deposits a high concentration of ACP in close proximity to the tooth surface (Azarpazhooh et al., 2008). The results of a study by Reynolds (1997) suggest that the remineralisation process involves diffusion of CaHPO, the neutral ion pair of calcium and phosphate ions that forms in the presence of acid, and associated calcium and phosphate ions through the protein/HO-filled pores of carious surface enamel into the body of the enamel lesion. Once in the body of the enamel lesion, these calcium and phosphate species, by dissociation, would increase the activities of $\mathrm{Ca}^{2+}$ and $\mathrm{PO}_{4}{ }^{3-}$. The CPP facilitates high concentrations of calcium and phosphate ions, including CaHPO, which can then diffuse into the enamel subsurface lesion and deposit into crystal voids of the demineralized enamel (Cochrane et al ., 2008). The CPP will also maintain the high activities of the free calcium and phosphate ions during remineralisation through the reserve of bound ACP. The bound ACP, by being in dynamic equilibrium with free calcium and phosphate ions, will maintain the concentrations of the species involved in diffusion into the lesion. Furthermore, dissociation of the CPP-bound ACP will be made possible by the acid generated by dental plaque bacteria. This would explain why the CPP-supported metastable calcium phosphate solutions are such efficient remineralizing solutions, since they would offset any fall in $\mathrm{pH}$ by generating more 
calcium and phosphate ions, including $\mathrm{CaHPO}$, thus maintaining their high concentration gradients into the lesion (Reynolds, 1997). It has been reported that CPP-ACP interacts with fluoride ions to produce novel nano-clusters of calcium, fluoride, and phosphate ions. The identification of this novel CPP-stabilized form of calcium, fluoride, and phosphate ions is consistent with the observed additive anticariogenic effects of the CPP-ACP nanocomplexes and fluoride. The anticariogenic mechanism of fluoride is the localization of the fluoride ion at the tooth surface. This localization promotes remineralisation of enamel with fluorapatite. It is clear that for the formation of fluorapatite, calcium and phosphate ions must also be present with the fluoride ions. The reported additive anticariogenic effect of CPP-ACP and fluoride may therefore be attributable to the localization of the novel calcium, fluoride, and phosphate ion nanoclusters at the tooth surface by CPP, which co-localizes calcium, phosphate, and fluoride as bioavailable ions in the correct molar ratio to form fluorapatite (Reynolds et al., 2008). CPP-ACP complexes have been shown to exhibit anticariogenic activity in laboratory, animal, and human in situ caries models. Further, CPP$\mathrm{ACP}$ has been shown to slow the progression of caries significantly and to promote the regression of early lesions in randomized, controlled clinical trials (Reynolds, 2009). One of the benefits of this peptide compound is that it has been shown to incorporate well into the salivary pellicle thereby inhibiting the adhesion of cariogenic bacteria, specifically S. Sobrinus and S. mutans, to the tooth surface (Schupbach, 1996). CPP-ACP has been tested as an additive in a variety of foods and oral care products including: chocolates, sugar-free gums, sports drinks, lozenges, glass ionomer cements, dentifrices, mouthwashes, and MI Paste ${ }^{\mathrm{TM}} / \mathrm{Tooth}_{\text {Mousse }}{ }^{\mathrm{TM}}$. Given that CPP-ACP can be incorporated into foodstuffs, as well as therapeutic agents, and demonstrates none of the adverse effects of fluoride overuse (i.e. fluorosis at moderate doses and toxicity at higher doses), it is possible that this product may become an important anti-caries agent in the future (Rose, 2000). The ability of the CPP-ACP technology added to sugar-free chewing gum to remineralize enamel subsurface lesions has been demonstrated in several randomized, controlled, double-blind in situ clinical studies. A study done by Cai et al. (2007) examined the effects of sugar-free gums (control and CPP-ACP-containing gums) chewed for either 20-minute periods four times daily or for 5-minute periods seven times daily on the remineralisation of carious enamel. Microradiography and densitometric image analysis demonstrated that, independent of gum type and chewing duration, the CPP-ACP nanocomplexes produced a dose-related remineralization of enamel subsurface lesions in situ. Gum containing $18.8 \mathrm{mg}$ and $56.4 \mathrm{mg}$ of the CPP-ACP nanocomplexes, chewed for 20-minute periods four times daily for 14 days, increased enamel subsurface remineralisation by $102 \%$ and $152 \%$, respectively, relative to the control sugar-free gum. Microradiographs of the enamel lesions before and after remineralisation showed that the CPP-ACP promoted remineralisation throughout the body of the lesion. Electron microprobe analyses of sections of the remineralized enamel indicated that the mineral deposited was hydroxyapatite with a higher $\mathrm{Ca}: \mathrm{P}$ ratio than normal apatite. Plus, this remineralized apatite was more resistant to acid challenge than the normal tooth enamel (Cai et al., 2007). Mouth rinses have also been shown to be effective in delivering CPP-ACP to the enamel surface. In a randomized, double-blind, cross-over study Reynolds et al . (2003) observed an increase in supragingival plaque calcium and inorganic phosphate levels of $118 \%$ and $57 \%$, respectively, using a 2\% CPP-ACP mouth rinse. The increase of calcium and phosphate ions within dental plaque was consistent with the proposed anticariogenic mechanism of CPP-ACP by maintaining the supersaturated state of remineralizing ions on the enamel surface. The investigators also reported that mouth rinses containing ACP without CPP did not exhibit increased calcium and inorganic phosphate levels. This is significant in that it demonstrates that CPP is essential in stabilizing and delivering ACP to the tooth surface. Although marked increases in plaque calcium, phosphate, and fluoride were found, calculus was not observed in any of the study participants, indicating that the calcium, fluoride, phosphate remained stabilized at the tooth surface by the CPP as bio-available ions and did not transform into a crystalline phase (Reynolds et al ., 2003). Addition of various concentrations of CPP-ACP into PowerAde ${ }^{\mathrm{TM}}$ sports drink (Coco-Cola, Atlanta) has demonstrated a significant reduction in the beverage's erosivity without affecting the products taste. While several articles have been published on the effectiveness of CPP-ACP in its pure form, studies involving commercially available MI Paste ${ }^{\mathrm{TM}}$ and MI Paste Plus $^{\mathrm{TM}}$ (or Tooth Mousse ${ }^{\mathrm{TM}}$ and Tooth Mousse Plus ${ }^{\mathrm{TM}}$ ) are limited, with the majority found in abstracts presented at International Association for Dental Research (IADR) conferences and funded by GC Corporation (Paterson, 2008; Sakaguchi, 2005, Sato, 2003). Although CPP-ACP is the main active ingredient in these products $(10 \% \mathrm{w} / \mathrm{v})$, it is uncertain whether incorporation into the form of a water-based, sugar-free paste alters its effective ability. An IADR abstract presented by Sato et al. (2003) confirmed the ability of Tooth Mousse ${ }^{\mathrm{TM}}$ to prevent the formation of caries in a bovine tooth model. Using Knoop Hardness measurements to evaluate treatment groups, those treated with Tooth Mousse ${ }^{\mathrm{TM}}$ displayed significantly less change in hardness reduction compared to a placebo paste and to a fluoridated paste. In addition, Sakaguchi et al.(2005) reported the ability of MI Paste ${ }^{\mathrm{TM}}$ to prevent acid-induced demineralization in bovine tooth enamel compared with a placebo paste, a $900 \mathrm{ppm}$ fluoride paste, and water. Samples were imaged using quantitative light-induced fluorescence (QLF) as well as x-ray CT. Researchers concluded that there was a significant protective effect of MI Paste ${ }^{\mathrm{TM}}$ in preventing the demineralization of enamel. 
Sakaguchi et al. (2005) later described a synergistic effect of CPP-ACP and fluoride, as found in Tooth Mousse Plus $^{\mathrm{TM}}$ (MI Paste Plus ${ }^{\mathrm{TM}}$ ), in remineralizing subsurface enamel lesions in bovine teeth. The casein phosphopeptides (CPPs) are produced from the tryptic digest of casein, aggregated with calcium phosphate and purified through ultra filtration (Sashi et al., 2013). CPP-ACP is the acronym for a complex of casein phosphopeptides and amorphous calcium phosphate (Goswami et al., 2012). This Recaldent technology was developed by Eric Reynolds, Australia. The CPP containing the amino acid cluster sequence - Ser (P)-Ser (P)-Ser (P)-Glu-Glu- has the ability to bind and stabilize calcium and phosphate in solution, as well as to bind dental plaque and tooth enamel. Through their multiple phosphoryl residues, the CPPs bind to form clusters of ACP in metastable solution, preventing their growth to the critical size required for nucleation and precipitation. The proposed mechanism of anticariogenicity for the CPP-ACP is that it localizes ACP in dental plaque, which buffers the free calcium and phosphate ion activities, thereby helping to maintain a state of super-saturation with respect to tooth enamel depressing demineralization and enhancing remineralisation. The CPPs have been shown to keep fluoride ions in solution, thereby enhancing the efficacy of the fluoride as a remineralizing agent (Goswami et al., 2012; Rose, 2000; Reynolds, 2008; Farooq et al., 2013; Mazzaoui et al., 2003). It can be delivered via tooth mousse, chewing gum, mouth rinses, toothpastes and reduction of tooth sensitivity (Farooq et al., 2013; Poitevin et al., 2004). CPP-ACP can be used to remineralise early carious lesions (Walsh, 2009). It has the ability to counteract the action of acids in cases of erosion (Piekarz et al., 2008). It has been proposed that CPP-ACP (Tooth-Mousse) has an edge over fluoride tooth paste when it comes to neutralizing acids in the oral cavity (Kariya et al., 2004; Al- Batayneh, 2009). CPP-ACP alone or its combination with fluoride can be utilized as a prophylactic agent before the bonding of orthodontic brackets (Tabrizi and Cakier, 2011). Recaldent ${ }^{\mathrm{TM}}$ influences the properties and behavior of dental plaque through binding to adhesion molecules on mutans streptococci and thus impairing their incorporation into dental plaque, elevating plaque calcium ion levels to inhibit plaque fermentation and providing protein and phosphate buffering of plaque fluid $\mathrm{pH}$ to suppress overgrowth of aciduric species under conditions where fermentable carbohydrate is in excess (Nidhi and Kunwarjeet, 2012; Morgan et al., 2008).

\section{Casein Phosphopeptide-Amorphous Calcium Fluoride Phosphate (CPP-ACPF, GC Tooth Mousse Plus ${ }^{\text {TM }}$, MI paste Plus ${ }^{\mathrm{TM}}$ ):}

A dentifrice containing CPP-ACP with fluoride provides remineralization which is superior to both CPP-ACP alone and to conventional and high fluoride dentifrices. This synergy between CPP-ACP and fluoride had been identified in studies which showed that MI Paste (without fluoride) remineralized initial enamel lesions better when applied as a topical coating after the use of a fluoride dentifrices (Nidhi and Kunwarjeet, 2012; Kumar et al., 2008). In the absence of such "environmental" fluoride, the predominant mineral that will be formed in enamel subsurface lesions during remineralization with CPP-ACP will be hydroxyapatite. It is now known that CPP can stabilize high concentrations of calcium, phosphate and fluoride ions at all $\mathrm{pH}$ values from 4.5 up to 7.0, and is able to remineralize enamel subsurface lesions observed at all $\mathrm{pH}$ values in this range, with a maximal effect at $\mathrm{pH} 5.5$ (Nidhi and Kunwarjeet, 2012). In fact, at $\mathrm{pH}$ values below 5.5, CPP-ACFP produces greater remineralisation than $\mathrm{CPP}-\mathrm{ACP}$, and the major product formed when remineralisation is undertaken with CPP-ACFP is fluorapatite, which is highly resistant to acid dissolution. The remineralised mineral was more resistant to subsequent acid challenge (Nidhi and Kunwarjeet, 2012; Iijima et al., 2004).

\section{Nano-Hydroxyapatite (Reminpro ${ }^{\mathrm{TM}}$ ):}

Hydroxyapatite (HA) is one of the most biocompatible and bioactive materials and is widely applied to coat artificial joints and tooth roots (Zhao et al., 2008). Hydroxyapatite is the mineral crystalline form of calcium and phosphorus found in the enamel, dentin, cementum, and bone. It is widely used in biology, medicine, and dentistry due to its optimal characteristics, such as similarity to the mineral structure of hard tissues, biocompatibility, and low solubility. It has remineralizing effects when applied to tooth enamel. Nano-hydroxyapatite (NHA), due to its higher surface/ volume ratio, is more effective than large HA particles. With the recent advances in nanotechnology, the size of particles has decreased and some modifications were made in their shape, yielding highly bioactive calcium phosphate compounds that may have higher potential for penetration into the porosities of the demineralized area as remineralising agents. The structure of enamel is too complex to be remodeled and the basic enamel building blocks are generally $20-40 \mathrm{~nm}$ hydroxyl apatite nano particles. Hence the remineralization of enamel minerals by using synthetic HA that resembles enamel HA may be beneficial (Swarup and Arathi, 2012). NovaMin ${ }^{\mathrm{TM}}$ is a synthetic mineral compound composed of calcium, sodium, phosphorus, and silica. It releases crystalline hydroxyl-carbonate apatite (HCA), which structurally resembles the minerals naturally found in the teeth. Nanohydroxyapatite (NHA) is a biocompatible compound with high affinity for tooth enamel. NHA particles morphologically resemble dental enamel apatite crystals and used rampantly now a days (Haghgoo et al., 2016). Nano-sized particles have similarity 
to the apatite crystal of tooth enamel in morphology (Vandiver et al., 2005). In recent years, an increasing number of reports have shown that nano-hydroxyapatite has the potential to remineralize artificial carious lesions following addition to toothpastes, mouthwashes.(Lu et al., 2007; Kim et al., 2007; Yamagishi et al., 2005). Nanohydroxyapatite was directly selected as a remineralizing agent and an in vitro pH-cycling model was used to evaluate the effect of four nano-HA concentrations on the initial enamel caries lesions. These results confirmed the ability of nano-hydroxyapatite to aid in remineralizing enamel; at each time point in the $\mathrm{pH}$-cycling, the different concentrations were directly related to the distinct effects on remineralization. The most likely explanation of the increased remineralization effect is that it was due to the ability of nanohydroxyapatite to promote remineralization. Nano-hydroxyapatite had the potential to remineralize initial enamel caries lesions under dynamic $\mathrm{pH}$-cycling conditions. A suspension of $10 \%$ nano-hydroxyapatite appeared to be the optimal concentration for remineralisation of early enamel caries. Nano-hydroxyapatite of proper concentration could therefore be beneficial in promoting remineralisation with regular daily usage. Various research findings concluded that nano-hydroxyapatite had the potential to remineralize initial enamel lesions. Given the small number of experiments and limitations of the invitro studies comparing the re-mineralizing potential of nano-hydroxyapatite toothpaste on enamel, the effectiveness of this toothpaste seems to be obvious in improving the initial enamel carious lesions. More research is needed to be carried out with clinical studies to substantiate the effectiveness of nano-hydroxyapatite on enamel.

\section{Bioactive Glass and Polyacrylic Acid-Modified Bio-active Glass Powder $\left(\operatorname{Novamin}^{\mathrm{TM}}\right.$ ):}

Bioactive glass was invented by Dr. Larry Hench in1960s (Shashi et al., 2013). NovaMin ${ }^{\text {TM }}$ is a bioactive glassceramic material, wherein the active ingredient is a calcium sodium phosphosilicate that reacts when exposed to aqueous media and provides calcium and phosphate ions that form a hydroxy-carbonate apatite (HCA) with time (Wefel, Js. 2009). NovMin ${ }^{\mathrm{TM}}$ adheres to exposed dentin surface and forms a mineralized layer that is mechanically strong and resistant to acid. There is continuous release of calcium over time, which maintains the protective effects on dentin (Burwell et al., 2010). It has been demonstrated that fine particulate bioactive glasses $(<90 \mu \mathrm{m})$ incorporated into an aqueous dentifrice have the ability to clinically reduce the tooth hypersensitivity through the occlusion of dentinal tubules by the formation of the CaP layer (Shashi et al., 2013). The NovaMin ${ }^{\mathrm{TM}}$ Technology was developed for use in dentistry by Dr. Len Litkowski and Dr. Gary Hack. Currently available products in the market are NovaMin ${ }^{\mathrm{TM}}$ SootheRx $^{\mathrm{TM}}$, DenShield ${ }^{\mathrm{TM}}$, NuCare ${ }^{\mathrm{TM}}-$ Root $_{\text {Conditioner with NovaMin }}{ }^{\mathrm{TM}}$, NuCare ${ }^{\mathrm{TM}}$ Prophylaxis Paste with NovaMin ${ }^{\mathrm{TM}}$, and Oravive ${ }^{\mathrm{TM}}$ (Goswami et al., 2010; Tai, 2006). In recent times, bioactive glass materials have been known to many fields of dentistry. This material has several distinctive features; the most significant among them is its ability to act as a biomimetic mineralizer, matching the body's own mineralizing traits. Bioactive glass was considered as a step forward in remineralization technology (Hassanein and El-Brolossy, 2006). Bioactive glass consists of minerals that occur naturally in body fluids and it reacts when it comes in contact with water, saliva or body fluid to release calcium, phosphorous, sodium and silicone ions in such a way that it results in the formation of hydroxyapatite crystals (HAP) (Oguntebi, 1993). An important finding in the remineralization concept was the effect of the concentration of calcium ions on the remineralisation process. Enamel white spot lesions can remineralise using bio-active glass and polyacrylic acid-modified bio-active glass powders. Mechanical properties of enamel were assessed using surface and cross-section Knoop microhardness. Micro- Raman spectroscopy in StreamLine ${ }^{\mathrm{TM}}$ scan mode was used to scan lesion cross-sections. The intensity of the Raman phosphate peak at $959 \mathrm{~cm} \_1$ was fitted and measured producing depth profiles analysed using a double-step fitting function. To obtain 3D images of surfaces using non-contact white light, profilometry permitting measurement of lesion step height in relation to the sound enamel reference level, and to scan the lesion surface using scanning electron microscopy (SEM). BAG (Bio active glass) and PAA-BAG (polyacrylic acid -bio active glass) surface treatments enhance enamel WSL (white spot lesion) remineralisation, assessed by the resultant improved mechanical properties, higher phosphate content and morphological changes within the artificial lesions. Minimally invasive dentistry encompasses the philosophy of preservation of the maximum quantity of repairable dental tissues and utilizing preventive, remineralisation approaches in incipient carious lesion management ((Banerjee, 2013; Mount, 2007). The enamel white spot lesion (WSL) is the earliest clinically evident manifestation of the caries process, exhibiting subsurface porosity caused by an imbalance between the biological dynamic processes of de- and remineralisation. In the minimally invasive reparative dentistry paradigm, incipient enamel carious lesions should not be managed with surgical intervention, but with non-invasive remineralisation strategies wherever possible (Mount, 2007). Bio-active glass (BAG) can act as a source of a large amount of $\mathrm{CaO}$ and $\mathrm{P}_{2} \mathrm{O}_{5}$ in a $\mathrm{Na}_{2} \mathrm{O}-\mathrm{SiO}_{2}$ matrix with a rapid dissolution rate and high ionic concentration (Hench, 2006). The bioactivity index determines the rate at which a bio-active material produces a chemical bond with a natural tissue. BAG 45S5 exhibits a high bioactivity index $(\mathrm{IB}=12.5)$ compared to other bio-active materials such as hydroxyapatite $(\mathrm{IB}=3)$, Thompson, (1998) and therefore it has the potential to remineralize enamel white spot lesions with an increased rate of HA 
(hydroxyapatite) formation. BAG has been introduced clinically as an air-abrasion abrasive powder to be used under the auspices of minimally invasive dentistry and has showed promising results for the controlled, selective removal of an enamel analogue substrate, demineralised enamel and resin composite restoration/cements, particularly using specific operating parameters (Milly, 2013). Polyacrylic acid (PAA) has been added to bio-active materials in order to mimic the functional role of non-collagenous proteins in binding the calcium and phosphate ions to form nanoprecursors, including amorphous calcium phosphate, small enough to penetrate the carious lesion more effectively (Kamitakahara, 2001). Using BAG powder containing $40 \mathrm{wt} \%$ PAA to treat the dentin using air abrasion technology reduced the micropermeability between the dentin and the adhesive layer in vitro, and might be a suitable strategy to enhance bond durability. Micro-Raman spectroscopy is used as a quantitative chemical assessment methodology for biological samples in conjunction with the fact that the Raman peak intensity is proportional to the number of molecules within the volume of scanned area (Tsuda and Raman, 1997). The Raman phosphate peak at $959 \mathrm{~cm} \_1$ characterizes tetrahedral $\mathrm{PO}_{4}$ group ( $\mathrm{P}-\mathrm{O}$ bond) within HA. Monitoring the intensity of this peak has been used to assess the degree of demineralization within enamel caries (Mohanty et al., 2012). To date, the use of Raman phosphate peak intensity measurement and high-speed line scanning to detect a potential increase in the phosphate content within the incipient lesion as a result of a remineralisation treatment has not been reported in the dental literature. Hardness measurements provide information about the mineral density and mechanical properties of hard tissue surfaces and are a reliable, objective method to study demineralised enamel and dentin lesions (Banerjee et al., 2010). The key approach in enamel WSL remineralisation is to utilize dissolvable materials containing ions required to deposit minerals similar to those of enamel and at the same time which can diffuse through the lesion. Biomimetic remineralisation of carious lesions has been reported using bio-active materials in the presence of protein analogues such as PAA to promote remineralisation through the lesion depth. BAG may enhance the remineralisation of demineralised dentine and inhibit the demineralisation of enamel (Sauro et al., 2011). Previous studies reported an increase in the mechanical properties of acid etched enamel and demineralised dentin treated by BAG paste (Burwell et al., 2009). This mechanical improvement could be caused as a result of "new" mineral deposition within the lesion, resulting from BAG 45S5 bioactivity process that forms HA layers at the interface level. The StreamLine ${ }^{\mathrm{TM}}$ Raman scanning is a high-speed line scanning system that allows faster and better excitation intensity distribution across the sample surface as it utilizes the Raman microscope optics to illuminate a moving line across the sample and to read the data continuously. The phosphate Raman peaks were observed within Raman spectra at the same positions detected in the literature (Tsuda and Raman, 1997. Peak intensity evaluation has been reported as a suitable parameter to detect a difference between sound and demineralised enamel regions. Using BAG, PAA-BAG and remineralisation solution did not reduce the lesion depth. This result may be explained as the calcium and phosphate ions' diffusion/precipitation may be restricted to the superficial area of the lesion inhibiting whole lesion remineralisation. This feature has been reported in the literature when different remineralisation agents were applied to treat enamel carious lesions (Pliska et al., 2012). To overcome this limitation, altering/modifying the lesion surface to improve mineral diffusion may still be required or even desirable (Crombie et al., 2013). Treating BAG particles with an aqueous solution such as saliva causes a leaching and exchanging of BAG ions with those in the solution and that in turn increases the interfacial $\mathrm{pH}$ followed by breaking $\mathrm{Si}-\mathrm{O}-\mathrm{Si}-\mathrm{O}-\mathrm{Si}-\mathrm{O}$ bridges and forming a $\mathrm{Si}(\mathrm{OH})_{4}$ layer. Calcium and phosphate ions are released from BAG, at this stage, to form an amorphous $\mathrm{CaP}$ layer, which is crystallized to a mixed hydroxyl-carbonate apatite layer (Hench et al., 2013). Rama phosphate peak intensity percentages were significantly higher within BAG, PAA-BAG groups compared to that of the negative control group implying that more phosphate ions were presented as a result of remineralisation treatment. The bioactive process of BAG and the precipitation of minerals at the lesion surface, observed within SEM images, may explain the higher Raman phosphate peak intensity monitored in the present study. The beneficial effect of utilizing bio-active glass and polyacrylic acid-modified bio-active glass powders in enamel white spot remineralisation paves the way for further investigation into the clinical application of such materials in the remineralisation of enamel in vivo under the auspices of minimally invasive reparative dentistry which advocates the preservation of repairable enamel structure and the use of remineralisation strategies to "heal" early lesions (Banerjee, 2013). The enamel treated with BAG and PAA-BAG exhibited improved mechanical proprieties and higher phosphate content enhancing the mineral depositions at the lesion surface. Smaller particle precipitations were detected within PAA-BAG compared to the BAG, and therefore this modification has a potential to promote entire mineral gain of treated lesions.

\section{Bibliography:-}

1. Aimutis, W. (2004). Bioactive properties of milk proteins with particular focus on anticariogenesis. J Nutr. 134: 989S-95S. 
2. Al-Batayneh Ola, B. (2009). The clinical applications of tooth mousse and other CPP-ACP products in caries prevention: evidence-Based recommendations. Smile Dent. J. 4(1):8-12.

3. Aminzadeh, A. Shahabi, S.,Walsh, L. J. (1999). Raman spectroscopic studies of CO2 laser-irradiated human dental enamel. Spectrochim Acta A. Mol. Biomol. Spectrosc. 55(6):1303-8.

4. Ardeshna, S.M., Qualtrough, A.J.E., Worthington, H.V. (2002). An in vitro comparison of pH changes in root dentine following canal dressing with calcium hydroxide points and a conventional calcium hydroxide paste. Int. Endo. J. 35(3): 239-244.

5. Azarpazhooh, A., Limeback, H. (2008). Clinical efficacy of casein derivatives: a systematic review of the literature. J. Am. Dent. Assoc. 139(7):915-24.

6. Banerjee, A. (2013). Minimal intervention dentistry: Part 7. Minimally invasive operative caries management: rationale and techniques. Br. Dent. J. 214:107-11.

7. Banerjee, A., Cook, R., Kellow, S., Shah, K., Festy, F., Sherriff, M., et al. (2010). A confocal micro-endoscopic investigation of the relationship between the microhardness of carious dentine and its autofluorescence. European J. Oral Sci.118:75-9.

8. Benson, P. (2008). "Evaluation of White Spot Lesions on Teeth with Orthodontic Brackets." Seminars in Orthodontics 14(3): 200-208.

9. Bergstrand, F., Twetman, S. (2003). "Evidence for the efficacy of various methods of treating white-spot lesions after debonding of fixed orthodontic appliances." J. Clin. Orthod. 37(1): 19-21.

10. Bishara, S.E., Ostby, A.W. (2008). "White Spot Lesions: Formation, Prevention, and Treatment." Seminars in Orthodontics 14(3): 174-182.

11. Boskey, A.L (1997). Amorphous calcium phosphate: the contention of bone. J. Dent. Res. 76(8):1433-1436.

12. Brochner, A., Christensen, C. et al. (2010). "Treatment of post-orthodontic white spot lesions with casein phosphopeptide-stabilised amorphous calcium phosphate." Clin. Oral Investig.

13. Burwell, A., Jennings, D., Muscle, D., Greenspan, DC. (2010). Novamin and dentin hypersensitivity- invitro evidence of efficacy. J. Clin. Dent. 21(3):66-71.

14. Burwell, A.K., Litkowski, L.J., Greenspan, D.C. (2009). Calcium sodium phosphosilicate (NovaMin): remineralization potential. Advances in Dent. Res. 21:35-9.

15. Cai, F., Manton, D.J., Shen, P., Walker, G.D., Cross, K.J., Yuan, Y., et al. (2007). Effect of addition of citric acid and casein phosphopeptide-amorphous calcium phosphate to a sugar-free chewing gum on enamel remineralization in situ. Caries Res. 41: 377-83.

16. Chang, H.S., Walsh, L. J. et al. (1997). "Enamel demineralization during orthodontic treatment. Aetiology and prevention." Aust. Dent. J. 42(5): 322-327.

17. Cochrane, N.J., Saranathan, S., Cai, F., Cross, K.J., Reynolds, E.C. (2008). Enamel subsurface lesion remineralisation with casein phosphopeptide stabilised solutions of calcium, phosphate, and fluoride. Caries Res. 42: 88-97.

18. Crombie, F.A., Cochrane, N.J., Manton, D.J., Palamara, J.E., Reynolds, E.C. (2013). Mineralisation of developmentally hypomineralised human enamel in vitro. Caries Res. 47:259-63.

19. Curzon M. (1983). Epidemiology of trace elements and dental caries In: Curzon M. and Cutress T. edt. Trace elements and dental disease. P.S.G. Inc. Boston. 11- 32.

20. Curzon, M. (1999). Tooth resistance factors in caries prediction In: Johnson N. W. edt. Risk markers for oral disease, vol. I. Cambidge University Press. New York. 189-217.

21. Dedhiya, M., Youg, F., Higuchi, W. (1974). Mechanism of hydroxyapatite dissolution. The synergistic effects of solution fluoride, Strontium and phosphate. J.Phys. Chem. 78: 1273-1279.

22. Duggal, M.., Chawala, H., Curzon, M. A. (1991). Study of the relationship between trace elements in saliva and dental caries. Arch. Oral Biol. $36-881$.

23. Eanes, E.D., Gillessen, I.H., Posner, A.S. (1965). Intermediate states in the precipitation of hydroxyapatite. Nature. 208:365-367.

24. El-Samarrai, S. (2001). Major and trace elements contents of permanent teeth and saliva among a group of adolescents in relation to dental caries and gingivitis and streptococci. Thesis submitted to College of Dentistry University of Baghdad.

25. Elzbieta, K., Surdacka, A., Matthews, T., Brzozowsk- Miskowiak, B. (2004). Digital image analysis and visualization of early caries changes in human teeth. Pielaszek Res. 11:21.

26. Estrela, C., Sydney, G.B., Bammann, L.L. and Felippe, Junior, O. (1995). Mechanism of action of calcium and hydroxyl ions of calcium hydroxide on tissue and bacteria. Braz. Dent. J. 6: 85-90.

27. Fang, M.M., Lei, K.Y., Kilgore, L.T. (1980). Effects of zinc deficiency on dental caries in rat. J. Nutri. 110: 1032-1036. 
28. Farooq, I., Imran, A., Moheet, Farooq, Z.I.U. (2013). A review of novel dental caries preventive material: Casein phosphopeptide-amorphous calcium phosphate (CPP-ACP) complex. King Saud University. J. Dent. Sci. 4(2):47-51

29. Feuerstein, O., Mayer, I., Deutsch, D. (2005). Physico-chemical changes of human enamel irradiated with ArF excimer laser. Lasers Surg. Med. 37(3):245-51.

30. Foreman, P.C. and Barnes, I.E. (1990). A review of calcium hydroxide. Int. Endo. J. 23(6): 283-297.

31. Goswami, M., Saha, S., Chaitra, T.R. (2012). Latest developments in non-fluoridated remineralizing technologies-review article. J. Indian Soc. Pedod. Prev. Dent. 30(1):2-6.

32. Graham, L., Cooper, P. R., Cassidy, N., Nor, J.E., Sloan, A.J., Smith, A.J. (2006). The effect of calcium hydroxide on solubilisation of bioactive dentine matrix components. Biomaterials. 27: 2865-73.

33. Gupta, K., Tewari, A., Sahni, A., Chawla, H.S. and Gauba, K. (1998). Remineralizing efficacy of a mineral enriched mouth rinse and fluoridated dentifrice on artificial carious lesions: an in vivo scanning electron microscopic study. J. Indian Soc. Pedod. Prev. Dent. 16: 67-71

34. Haghgoo, R; Ahmadvand, M and Moshaverinia, S. J. (2016). Remineralizing Effect of Topical NovaMin and Nanohydroxyapatite on Caries-like Lesions in Primary Teeth. Contemp. Dent. Pract.17 (8): 645-649.

35. Hassanein, O.E., El-Brolossy, T.A. (2006). An investigation about the remineralization potential of bio-active glass on artificially carious enamel and dentin using Raman spectroscopy. Egypt J. Solids. 29:69-80.

36. Head, J.A. (1912).A study on saliva and its action on tooth enamel in reference to its hardening and softening. J. Am. Med. Assoc.59: 2118-2122.

37. Hench, L.L. (2006). The story of bioglass. J. Mater. Sci. Mater. Med. 17:967-78.

38. Hench, L.L. (2013). An introduction to bioceramics. London: Imperial College Press; 2013. Effect of Selected Metal Salts on the Microscopical. 7(2): 201198

39. Hilton, T. (2009). Keys to clinical success with pulp capping: A review of the literature. Oper. Dent. 34: 61525.

40. Iijima, Y., Cai, F., Shen, P., Walker, G., Reynoldes, E.C. (2004). Acid resistance of enamel subsurface lesions remineralized by a sugar free chewing gum containing casein phosphopeptide amorphous calcium phosphate. Caries Res. 38(6):551-6

41. Kamitakahara, M., Kawashita, M., Kokubo, T., Nakamura, T. (2001). Effect of polyacrylic acid on the apatite formation of a bioactive ceramic in a simulated body fluid: fundamental examination of the possibility of obtaining bioactive glassionomer cements for orthopaedic use. Biomaterials 22:3191-6.

42. Kardos, S., Shi, B., Sipos, T. (1999). The in vitro demineralization potential of a sodium fluoride, calcium and phosphate ion-containing dentifrice under various experimental conditions. J. Clin. Dent. 10 (1): 22-25.

43. Kariya, S., Sato, T., Sakaguchi, Y., Yoshii, E. (2004). Fluoride effect on acid resistance capacity of CPP-ACP containing material. Abstract 2045. 82nd General Session of the IADR, Honolulu, Hawaii.

44. Karlinsey, R.L., Mackey, A.C., Walker, E.R., Amaechi, B.T., Karthikeyan, R., Najibfard, K. et al. (2010). Remineralization potential of $5000 \mathrm{ppm}$ fluoride dentifrices evaluated in a pH cycling model. J. Dent. Oral Hyg. 2:1-6

45. Karlinsey, R.L., Mackey, A.C., Walker, E.R., Frederick, K.E. (2010). Surfactant-modified -TCP: Structure, properties, and in vitro remineralization of subsurface enamel lesions. J. Mater. Sci. 21(7):2009-20.

46. Kato, S., Fusayama, T. (1970). Recalcification of artificially decalcified dentin in vivo. J. Dent. Res. 49:10601067.

47. Kim, M. Y., Kwon, H. K., Choi, C. H., Kim, B. I. (2007). Combined effects of nano-hydroxyapatite and NaF on remineralization of early caries lesion Key Eng. Mater. 330-332:1347-50.

48. Kumar, V.L., Itthagarun, A., King, N.M. (2008). The effect of casein phosphopeptide amorphous calcium phosphate on remineralization of artificial caries like lesions: an invitro study. Aust. Dent. J. 53(1):34-40.

49. Lau, P.Y.,Wong R.W. (2006). "Risks and complications in orthodontic treatment." Hong Kong Dental Journal 3(1): 15-22.

50. Laurence, J. Walsh. (2009). Contemporary technologies for remineralization therapies: A rev. Int. Dent.11 (6):6-16.

51. Livas, C., Kuijpers-Jagtman, A. M. et al. (2008). "Quantification of white spot lesions around orthodontic brackets with image analysis." Angle Orthod. 78(4): 585-590.

52. Lu, K. L., Zhang, J. X., Meng, X. C., Li, X. Y. (2007). Remineralization effect of the nano-HA toothpaste on artificial caries Key Eng. Mater. 330-332 267-705 Biomed. Mater. 4 0: 341-344.

53. Lynch, E., Baysan, A. et al. (2000). "Effectiveness of two fluoride dentifrices to arrest root carious lesions." Am. J. Dent. 13(4): 218-220.

54. Mazzaoui et al. (2003). Incorporation of CPP-ACP into glass ionomer cement. J. Dent. Res. 82 (11):914-918. 
55. Mcclure, M J. (1963). Further studies on the cariostatic effect of organic and inorganic phosphates. J. Dent. Res.42 (69):3-9

56. Mellberg, J. R. (1990). Evaluation of topical fluoride preparation. J. Dent. Res. 69:771-779.

57. Mickenautsch, S., Yengopal, V. and Banerjee, A. (2010). Pulp response to resin-modified glass ionomer and calcium hydroxide cements in deep cavities: A quantitative systematic review. Dent. Mater. 26: 761-70

58. Milly, H., Austin, R., Thompson, I., Banerjee, A. (2014). In-vitro effect of air-abrasion operating parameters on dynamic cutting characteristics of alumina and bio-active glass powders. Operative Dentistry. 39 (1): 81-89..

59. Mohanty, B., Dadlani, D., Mahoney, D., Mann, A.B. (2012). Characterizing and identifying incipient carious lesions in dental enamel using micro-Raman spectroscopy. Caries Res. 47:27-33.

60. Morgan, M.V., Adams, G.G., Bailey, D.L., Tsao, C.E., Fischman, S.L., Reynolds, E.C. (2008). Anticariogenic effect of sugar free gum containing CPP-ACP nanocomplexes approximal caries determined using digital bitewing radiography. Caries Res. 42(3):171-84.

61. Mount, G.J. (2007). A new paradigm for operative dentistry. Australian Dental J. 52:264-70.

62. Murry, J. J. (1996). The prevention of oral disease. The carious lesion in enamel 3rd edt. Oxford University Press New York. 231-281.

63. Nidhi, G., Kunwarjeet, S. (2012). Try to believe it-amazing Remineralizing technologies. J. Pharm. Biomed. Sci. 24(24): 79-82.

64. Oguntebi, B., Clark, A., Wilson, J. (1993). Pulp capping with Bioglass and autologous demineralized dentin in miniature swine. J. Dent. Res. 72:484-9.

65. Palazzi, S. (1966). Sur les mineralisation et remineralisation de la dentine. Bull Group Int. Rech. Sc. Stomat. 9:257-266

66. Paterson, I.J; Clough, T.N. and Anderson, P. (2008). Calcium ion release from a commercial Tooth Mousse ${ }^{\mathrm{TM}}$. IADR General Session. Abstract 452. Toronto, Canada.

67. Peter, S. (2004). Essentials of Preventive sand Community Dentistry 2nd edt. Publishingttause. Darya Gani New Delhi.

68. Piekarz, C., Ranjitkar, S., Hunt, D., McIntyre, J. (2008). An in vitro assessment of the role of tooth mousse in preventing wine erosion. Aust. Dent. J. 53( 1):22-5.

69. Pliska, B.T., Warner, G.A., Tantbirojn, D., Larson, B.E. (2012). Treatment of white spot lesions with ACP paste and microabrasion. Angle Orthodontist. 82:765-9.

70. Poitevin, A., Peumans, M., de Munck, J., van Landuyt, K., Coutinho, A., et al. (2004). Clinical effectiveness of a CPP-ACP creme for tooth hypersensitivity treatment. EADR 2004 abstract no. 01.

71. Pulido, M.T., Wefel, J.S. et al. (2008). "The inhibitory effect of MI paste, fluoride and a combination of both on the progression of artificial caries-like lesions in enamel."Oper. Dent. 33(5): 550-555.

72. Reeves, R.E and Latour, N.G. (2009). Calcium phosphate sequestering phosphopeptide from casein. Science. 128: 472, 1958. Rehder Neto FC, Maeda FA, Turssi CP, Serra MC. Potential agents to control enamel carieslike lesions. J. Dent. 37(10): 786-90.

73. Reynolds, C. (2009). Casein phosphopeptide-amorphous calcium phosphate: the scientific evidence. Advances Dent. Res. 21: 25-29.

74. Reynolds, E.C. (1987). The prevention of sub-surface demineralization of bovine enamel and change in plaque composition by casein in an intra-oral model. J. Dent. Res. 66(6): 1120-7.

75. Reynolds, E.C. (1997). Remineralization of enamel subsurface lesions by casein phosphopeptide-stabilized calcium phosphate solutions. J. Dent. Res. 76(9): 1587-95.

76. Reynolds, E.C. inventor. (1991). The University of Melbourne and The Victorian Dairy Industry Authority, assignees. Anticariogenic phosphopeptides. US Patent 5:015-628.

77. Reynolds, E.C., Cai, F., Shen, P., Walker, G.D. (2003). Retention in plaque and remineralization of enamel lesions by various forms of calcium in a mouthrinse or sugar-free chewing gum. J. Dent. Res. 82(3): 206-211.

78. Reynolds, E.C., Cain, C.J., Webber, F.L., Black C.L., Riley, P.F., Johnson, I.H., et al. (1995). Anticariogenicity of tryptic casein and synthetic-phosphopeptides in the rat. J. Dent. Res. 74: 1272-79.

79. Reynolds. (2008) Calcium phosphate-based remineralization systems: Scientific evidence? Aust. Dent. J. 53(3):268-73.

80. Rose, R.K. (2000). Effects of an anticariogenic casein phosphopeptide on Ca diffusion in streptococcal model dental plaques. Arch. Oral Biol. 45(7):569-75.

81. Sakaguchi, Y., Kato, S., Sato, T., Kariya, S., Chen, L. (2005). Preventing acid induced enamel demineralization using CPP-ACP containing paste. IADR General Session. Abstract 2055. Baltimore, Maryland, USA.

82. Sashi, P. T., Garg, P., Sinha D. J., Singh U. P. (2013). An update on Remineralizing agents. J. Interdisciplinary Dent.3(3):151-158. 
83. Sato, T., Yamanaka, K., Yoshii, E. (2003) Caries prevention potential of a tooth-coating material containing casein phosphopeptide-amorphous calcium phosphate (CPP-ACP). IADR General Session. Abstract 1007. Göteborg, Sweden.

84. Sauro, S., Thompson, I., Watson, T.F. (2011). Effects of common dental materials used in preventive or operative dentistry on dentin permeability and remineralization. Operative Dentistry. 36:222-30.

85. Schmit, J.L; Staley, R.N; Wefel, J.S; Kanellis, M; Jakobsen, J.R and Keenan, P.J. (2002). Effect of fluoride varnish on demineralization adjacent to brackets bonded with RMGI cement. Am. J. Orthod. Dentofac. Orthop. 122(2): 125-34.

86. Schupbach, P., Neeser, J.R., Golliard, M., Rouvet, M., Guggenheim B. (1996). Incorporation of caseinoglycomacropeptide and caseinophosphopeptide into the salivary pellicle inhibits adherence of mutans streptococci. J. Dent. Res. 75: 1779-88.

87. Shaw, H. (1954). The effect of carbohydrate-free and carbohydrate-low diets on the incidence of dental caries in white rats," J. Nutr. 53: 151-162.

88. Sullivan. R.J., Charig, A., Haskins, J.P., Zhang, Y.P., Miller, S.M., Strannick, M., et al. (1997). In vivo detection of calcium from dicalcium phosphate dihydrate dentrifrice in demineralized human enamel and plaque. Adv. Dent. Res. 11(4):380-7.

89. Swarup, J.S., Arathi, R. (2012). Enamel surface cremineralization: Using synthetic hydroxyapatite. Contemp. Clinic. Dent. 3(4):433-436.

90. Tabrizi, A., Cakirer, B. (2011). A comparative evaluation of casein phosphopeptide-amorphous calcium phosphate and fluoride on the shear bond strength of orthodontic brackets. Eur. J. Orthod. 33(1): 282-7.

91. Tai, B.J., Bian, Z., Jiang, H. (2006). Anti-gingivitis effect of a dentifricecontaining bioactive glass (NovaMin) particulate. J. Clin. Periodontol. 33(2):86-91.

92. Thompson, I.D., Hench, L.L. (1998). Mechanical properties of bioactive glasses, glass-ceramics and composites. Proceedings of the Institution of Mechanical Engineers, 212:127-36.

93. Torredo, A., Valiente, M., Zhang, W., Liy;-Munozic, A. (2004). Re mineralization potential of anew tooth poste formation an in vitro study. J. Contemp. Dent. Practi. 15(5):18-30.

94. Tsuda, H., Raman, A. J. (1997). spectroscopy in dental research: a short review of recent studies. Advances in Dent. Res. 11:539-47.

95. Tufekci, E., Dixon, J.S. et al. (2011). "Prevalence of white spot lesions during orthodontic treatment with fixed appliances." Angle Orthod. 81(2): 206-210.

96. Tung, M.S., Eichmiller, F.C. (1999). Dental Applications of Amorphous Calcium Phosphates. J. Clin. Dent. 10(1):1-6.

97. Vandiver, J., Dean, D., Patel, N., Bonfield, W., Ortiza, C. (2005). Nanoscale variation in surface charge of synthetic hydroxyapatite detected by chemically and spatially specific high-resolution force spectroscopy. Biomaterials. $26: 271-83$

98. Walsh, L. MI paste and M.I paste plus. (2009). Anthology of applications. Availablefrom: $<\mathrm{http}: / / \mathrm{www}$.gcamerica.com/products/hp/ Paste/mipaste_cookbook. pdf $>$ accessed 10.02.2009.

99. Wefel, J.S. (2009). Novamin likely clinical success. Adv. Dent. Res. 21: 2009. DOI: $10.1177 / 0895937409335622$.

100.Willmot, D. (2008). "White Spot Lesions After Orthodontic Treatment." Seminars in Orthodontics. 14(3): 209219.

101.Yamagishi, Y., Onuma, K., Suzuki, T., Okada, F., Tagami, J., Otsuki, M., Senawangse, P. (2005). A synthetic enamel for rapid tooth repair. Nature. 433: 819

102.Zhao Jie; Yu, Liu; Wei-bin, S and Zhang, H. (2011). Amorphous calcium phosphate and its application in dentistry. Chemistry Central Journal 5:40 http://journal.chemistrycentral. com/content/5/1/40

103.Zhao, H., W, He., Wang, Y., Zhang, X., Li, Z., Yan, S., Zhou, W., Wang, G. (2008). Biomineralization of large hydroxyapatite particles using ovalbumin as biosurfactant. Mater. Lett.62 3063-5. 